Session 2520

\title{
Computer Integrated Robust 3D Modeling and Analysis: A Required Tool for the Modernization of Design in Curriculum
}

\author{
Hamid Khan \\ East Carolina University \\ Greenville, NC 287858 \\ khana@mail.ecu.edu
}

\begin{abstract}
Present day industries are specific about the acquired capabilities of Design Stream graduates in engineering technology programs. Their concerns are predicated on the fact that graduates are not able to produce effective results as designers in their design teams immediately. This lack of effectiveness is attributable to the lack of cohesive focus on the program's integration of the design curriculum. Engineering technology design curriculum is compartmentalized, and the students are not ready for contribution to the design team - the industries say. This allegation is partly true, as there is no effective means of student integration of design concept into an industrially sound application, using an industrially robust three-dimensional design and manufacturing package.
\end{abstract}

This paper will study the effectiveness of an Engineering Technology Program-Design concentration, via the traditional emphasis without an industrially capable integrated $\mathrm{cad} / \mathrm{cam}$ software. The program effectiveness will be evaluated by Outcome Based program Evaluation and Review Technique. Next the program will be studied along a different stream with the integration of a capable and robust $3 \mathrm{D}$ cad/cam/analysis software package. And the same criteria of program effectiveness will be used to compare the achievement and performance of the program.

This is an evaluative study of efforts to integrate the design curriculum with a comprehensive unifying design software. Twenty final year students in a capstone "Machine and Tool Design" course used the robust design software. At he culmination of the course they were asked about their design skill experience and the effectiveness of the course. The survey revealed that "Student learning and professional design development was enhanced with the use of an effective cad/cam integration tool that enabled students to synthesize design problems which were challenging and practical." The result of this research is crucial to the Accreditation Board for Engineering and Technology's (ABET2000) outcome based evaluation criteria and its implementation.

\section{Introduction}

About ten years ago, the ongoing debate in this relatively young Computer Aided Design industry was, "What does the D in CAD stand for?" Some thought Drafting and others thought Design. Still others included both: CADD. In education, D usually meant drafting. The integration of mainstream CAD into the curriculum was dominated by a $2 \mathrm{D}$ approach. First generation CAD tools were limited, difficult, and could not take the student very far beyond the traditional practice of $2 \mathrm{D}$ drafting. Students became CAD 
operators. CAD operators became a glut in the market. Learning using 3D design CADD was still a vision, and not a reality.

Those pioneers were quickly becoming outdated, largely due to the advances made in operating system and computer graphics technology. A new generation of developers is now introducing extra-ordinary levels of power, productivity, and ease of use that has never been seen before. This second phase of CAD development allows educators to break free from the limitations of clumsy 2D based systems, and finally focus on the principles of visual communication, design process, and problem solving. CAD solutions have been the primary catalyst for this modern, new phase of CADD education in the design curriculum.

Engineers and technologists must learn about how to think in the modern world of product and systems design, facilities layout and planning and manufacturing [1]. We indeed have made great efforts toward integrating CAD into design and manufacturing curriculum but we are still limited by what we see as automated 2D drafting.

\section{Curriculum Design Using Robust 3D Modeling / Design Software}

The vision of CAD's role in engineering and technology education is:

- CAD software is intuitive and user friendly

- Needless time and effort must not be expended in wrestling with the software to learn the software.

- Both the teachers and students will maximize their time learning to be design and manufacturing professionals.

- Cost of entry to the CAD environment is much lower, and the payoff much higher.

- That the students will understand the enormous impact that a true 3D design process can have on a modern product design and manufacturing process.

- That they will understand the potential of rapid prototyping, computer generated animation

With the above principle in mind, it has been decided to effect the following integration in the design manaufacturing curriculum.

- A common integrated computer-aided engineering software package that covers drafting, analysis, manufacturing and other application of design courses

- The materials that are most relevant to concurrent teaching in a parallel fashion include design, manufacturing, design and production economics, quality control

- The senior machine and fixture design course, which allows a comprehensive treatment of concurrent engineering paradigm is to be handled by one comprehensive software of industrial strength. 


\section{Target Courses affected in Present Curriculum}

There were two streams of courses that were affected by this vertical integration of new modeling techniques and concurrent engineering. These are: Design Concentration and Manufacturing Concentration.

\section{A. Design and Drafting (DESN)}

2034 Engineering Graphics I: Computer related elective. Survey communications course that gives the basic skills and theory of graphics. Application of graphics in manufacturing, construction, and related fields.

2036 Computer-Aided Design and Drafting Study and application of computer-aided as it relates to the design process and development of engineering drawings and other documents. Use of CADD in various design disciplines, including architectural, electrical, mechanical, and civil, will be examined.

3030 Architectural Design. Introduction to the fundamental residential drawings 3032 Engineering Graphics. Continuation with greater depth in the application of graphics in manufacturing construction and related fields.

3036 Architectural Design and Drafting. Practical experience in the design of commercial structures from the graphics perspective and development and interpretation of working drawings.

4030 Descriptive Geometry. Principles of projection, including reference system (the graphical method of solving solid analytic geometry problems).

4234 Machine and Tool Design. Study and application of the principles of machine and tool design. Students will be required to complete designs and drawings of machines, tools, fixtures, gauges, automated clamping devices, and piercing and forming dies.

4503. Laboratory Problems: Design and Drafting Independent study, which provides the opportunity to gain further expertise in a particular area of design and drafting.

4504. Laboratory Problems: Graphic Communication. Independent study of concepts, processes, tools, and materials in the field of graphic communication technology.

5500. Independent Study: Graphic Communication Research-oriented course in problem solving in the field of graphic communication.

\section{B. Manufacturing (MANF)}

3500. Automation Systems. Study of the basic types of automated systems commonly used in industry, including control systems and common types of computer applications in the design, development, and management of automated manufacturing systems.

\section{Target Courses affected in Present Curriculum}


4020 Process System Design. Study, planning, and selection of processes for manufacturing various products. Emphasis is placed on selection criteria such as safety, material, jigs, fixtures, layout, and overall efficiency.

4023. Process System Planning and layout of a processing system for manufacturing of a line product. Emphasis is placed on process design, costing, control systems, and setup.

4502. Laboratory Problems: Independent study of industrial manufacturing systems, processes, and concepts.

4507. Laboratory Problems: Metals. In depth and independent study of concepts and/or processes of the metals area, its tools, and materials, with a strong emphasis on lab work.

5504. Independent Study: Manufacturing Research-oriented course in problem solving with the tools, materials, and processes of the manufacturing industries.

\section{Design/Manufacturing Across the Curriculum: using IDEAS}

Development of an Integrated Design/ Manufacturing Curriculum Across the (Undergraduate) Curriculum has both effective and practical value that has long been felt, but was not enforced due to a lack of robust cad/cam/cae/rapid prototyping software. As accreditation guidelines by ABET for engineering technology program lately became quite stringent in core competency requirement in the area of the product realization process, the schools committed themselves to teaching and integrating design and manufacturing education across curriculum.

\section{The Process Capability of Integration}

The most common methods used to represent an object in computer aided design systems that require High Performance Computing and Graphics are wire-frame, surface and solid modeling capability.

IDEAS, our integrating medium and other advanced engineering design/ manufacturing software, have techniques supported by most solid modelers with integrated CAD/ CAE/ CAM capabilities with VGX (Variational Graphics Extension) technology that requires High Performance Computation.

Technology used in parts and assemblies modeling require new functionality and enhancements throughout the CAD, CAM, and CAE applications.

From concept design through manufacturing and product evaluation, integrated CAD systems provide advanced functionality they need to get their products modeled with concurrent engineering applications. Success in today's engineering classroom hinges on a school's ability to bring increasingly complex products to classroom and design and produce faster than ever before. Driven by time-to-market the students with modeling agility, these curricular advances are demanding integrated technologies and processes 
that speed every aspect of product engineering and manufacturing, without compromising quality or innovation. It was with these goals in mind that advanced integrated CAD systems were developed for the broadest and strongest software suite in the industry for complete product development and come to universities for their integration capabilities.

Design, product engineering and manufacturing are collaborative in efforts and require much cross-curricular endeavors for integration. Integrated CAD support these complex environments through master modeling technique and integrated data management capabilities. This latest modeling software enables manufacturing annotations to be added directly to the master model. Additionally, dimensions, annotations and URL's are fully supported in VRML output to enable further research collaborations.

The integration effort in our advanced platforms have seamlessly combined the nine core application sets: Modal Analysis, Core Master Modeler, Core Drafting, Core Testing, Surfacing Set, Assembly Set, Simulation Modeling Set, Simulation Solution Set, Manufacturing Set and Advanced Manufacturing Set.

\section{Step-by-Step Integration}

The Design to Manufacture concept was tried in the advanced level capstone course DESN 4032: Machine and Tool Design, which is amenable to a trial application. This trial application was completed as a pilot study to learn about the impact of integration on a specific course in order to effectively translate it to other courses and then to the program at large.

\section{New Outcome based Evaluation Criteria for Design and Manufacturing Sequence incorporating IDEAS Design-Manufacturing-Finite Element Analysis Simulation}

The challenge is on writing outcome level statements with specific evaluation criteria. Precisely boiling it down to at least three elemental levels, activity oriented behavioral statements, with a high order cognitive, affective, and psychomotor component offers greatest effectiveness in questionnaire design for use. This whole exercise makes the educational evaluation endeavor more scientific and defensible. Design of evaluation questionnaire starts from the objective of outcomes assessment on the behavioral level. Some authors have addressed this difficulty well [2]. Figure 1 shows the assembly of a comprehensive IDEAS project from which outcome statements of "students ability" were written and expanded. The IDEAS student group showed excellence in these three levels of behaviors attributed to the evaluation methodology used by Newcomer (1983). [3] 

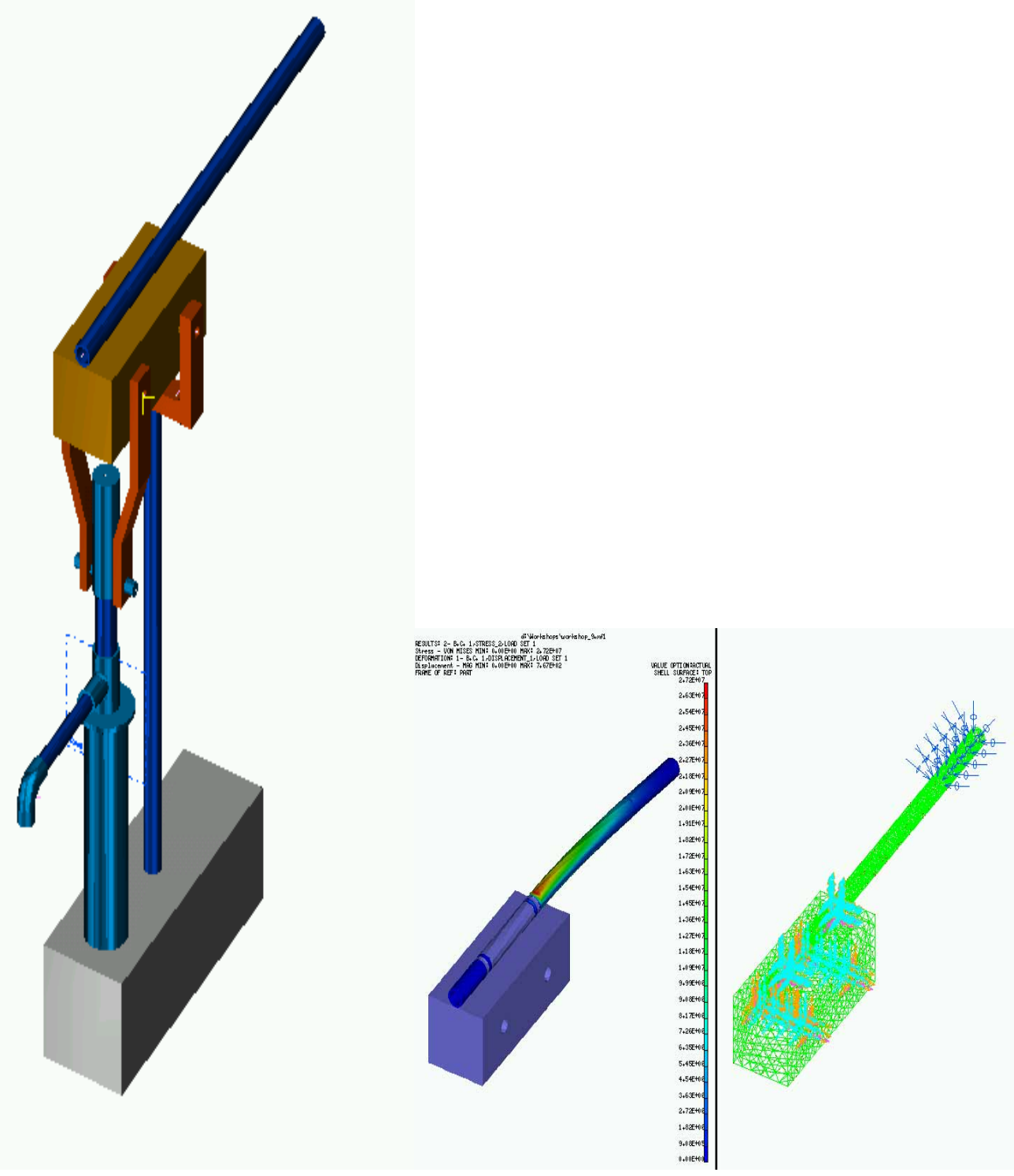

Fig. 1 Complete Model of a Pump Assembly that was designed by students in a design--draftinganalysis-simulation course with interactive parts for a Capstone Project. Activity Level Behavior Statements were derived from the "student ability to perform."

\section{Effectiveness of teaching and learning}

A study was made for one course entitled "Machine Tool and Fixtures Design" a senior level course with the following emphasis. The following broad or general list summarizes the learning objectives of the course.

1. Learning and Using the IDEAS software

- Part Modeling

- Modifying Parts

- Constrains and Constraint Networks

- Surface Modeling Techniques

- Team work in modeling 


\section{Application using IDEAS software}

- Design Application

- Drafting Application

- Simulation Application

\section{Steps and strategies used in developing Outcomes Based Evaluation Questionnaire}

Schon (1983) stresses that reflective practice demonstrating the outcomes of learning is grounded in the students' appreciation of the system (i.e. repertoire of values, knowledge, theories, and implied practices expected of the student learners) [4]. Consequently the preparation of reflective student practitioners requires not only the elements of the reflective process but also increasing the range and depth of knowledge in each student's appreciation of the system.

The strategies suggested for the development and inclusion of student reflection in projects included (a) Communicating that knowledge is socially constructed - students were given ample opportunities to realize this in the project-oriented course. (b) Modeling reflection, that means the theory is set to practice. (c) Providing guided practice in reflective thinking and execution of project tasks. [5]

\section{Outcome Level Statements (each statement encompasses higher order Cognitive, Affective and Psychomotor Skills)}

There are two stages of questionnaire development. Definition of General Outcome Level Statements (broad statements) and Specific Activity Level Behavioral Statements. The following are the broader level general statements of outcome:

1. Students will solve design conceptualization and perception problems.

2. Students will master computer aided design and manufacturing

3. Students will demonstrate skills in solving applied industrial problems

4. Students will integrate all aspects of design and manufacturing in the capstone project course.

5. Students will apply their breadth of design and manufacturing skills in coop programs.

6. Students will evaluate their own competitive advantage using an integrated design software.

7. Students will exhibit confidence of competent industrial designers and technologists.

\section{"Behaviors Acceptable as Evidence of Success" using the Robust 3D Modeling Software}

Related three levels of behaviors are listed that pertain to higher order Cognitive, Affective and Psychomotor domains.

The following activity level statements are in the specific behavioral level. $a=$ cognitive domain; $b=$ affective domain; $\mathrm{c}=$ Psychomotor skills domain. Criteria are in bold letters.

1. a. Students will solve design conceptual problems by computer

b. Students will solve design visualization problems by computer

c. Students will solve mental rotation problems by computer

2. a. Students will design a working product using $C A D$

b. Students will analyze a working product using CAE

c. Students will fabricate a working product using CAM

3. a. Students will learn about function of an industrial product

b. Students will design and fabricate an industrial product

c. Students will test and evaluate the industrial product

4. a. Students will use effectively, integrated CAD/CAE/CAM software in the final capstone project

b. Students will be competent in articulating facets of design and manufacturing in the final capstone project 
c. Student will demonstrate skill integration in the final capstone project

5. a. Students will solve coop design assignments via CAD/CAE/CAM

b. Students will use these CAD/CAE/CAM tools effectively on coop jobs

c. Students will apply integrated skills in coop jobs

6. a. Students will demonstrate competitive edge

b. Students will demonstrate cad-leadership quality

c. Students will exhibit pride in cad-profession

7. a. Students will exhibit competence as entry level engineers

b. Students will design safe products from skills learned

c. Students will be competent applied engineers/ technologists

\section{Outcomes Based Survey Questionnaire and Summary of Responses}

There were twenty responses to the survey with $n=20$. The questions were five point Likert Type with Strongly Agree $=5$, Agree $=4$, Neutral $=3$, Disagree $=2$ and Strongly Disagree $=1$. These questions were derived from the behavioral level outcome statements reflecting the three important domains in Bloom's Taxonomy as described above. For the brevity of reporting the Means (Medians) of the responses have been highlighted. For instance for the question number 1, most of the respondents (fourteen of twenty) "agreed", three "strongly agreed" and three were "neutral". So Agree=4 has been highlighted as a mean and median.

1. This course helped me solve design conceptual problems.

2. This course helped me solve design visualization problems

3. This course helped me solve mental rotation design problems

4. This course helped me design a working product using CAD

5. This course helped me analyze a working product using CAE

6. This course helped me manufacture a working product using CAM

7. This course helped me learn about the functions of an industrial product

8. This course helped me design and manufacture an industrial product

9. This course helped me test and evaluate the industrial product

10. This course helped me use effectively, integrated CAD/CAE/CAM software in the final capstone project

11. This course helped me to become competent in articulating facets of design and manufacturing in the final capstone project.

12. This course helped me demonstrate skill of integration in the final capstone project.

SA $5 \begin{array}{lllllll} & 3 & 2 & 1 & \mathrm{SD}\end{array}$

SA $5 \begin{array}{lllllllll}4 & 3 & 2 & 1 & \text { SD }\end{array}$

13. This course helped me solve co-opted design assignments via CAD/CAE/CAM.

SA $54 \begin{array}{lllll} & 4 & 2 & \text { SD }\end{array}$

14. This course helped me use these $\mathrm{CAD} / \mathrm{CAE} / \mathrm{CAM}$ tools effectively on co-opted jobs

SA $5 \begin{array}{lllllllllll}4 & 3 & 2 & 1 & \text { SD }\end{array}$

15. This course helped me apply integrated skills in co-opted jobs

16. This course helped me demonstrate competitive edge of design

17. This course helped me demonstrate applied CAD-leadership

18. This course helped me exhibit pride in cad-profession

19. This course helped me exhibit competence as entry level engineers

20. This course helped me design safe products from skills learned

SA $5 \begin{array}{lllllllll} & 4 & 3 & 2 & 1 & \text { SD }\end{array}$

SA $5 \begin{array}{lllllllll} & 4 & 3 & 2 & 1 & \text { SD }\end{array}$

SA $5 \begin{array}{llllll}4 & 3 & 2 & 1 & \text { SD }\end{array}$

SA $5 \begin{array}{lllllllllll}4 & 3 & 2 & 1 & \text { SD }\end{array}$

SA $5 \begin{array}{lllllllllll} & 4 & 3 & 2 & 1 & \text { SD }\end{array}$

SA $54 \begin{array}{llllllll} & 4 & 2 & 1 & \text { SD }\end{array}$

21. This course helped me become a competent and applied engineer/ technologist SA $5 \begin{array}{lllllll}5 & 4 & 2 & 1 & \text { SD }\end{array}$

\section{Evaluation and Result:}

There are twenty-one evaluative questions in the questionnaire with various quality criteria built into each item These questions are scrambled so the students will not be able to guess. These quality criteria are derived from Bloom's taxonomy ranging from lower level knowledge to higher level synthesis and 
application. Since the questionnaire has been developed from the outcomes statements, which is a reflection of the "objective and quality," those seven criteria of quality are also embedded in the questions. The highlighted "elements of quality" are also apparent in the seven basic statement stated above.

Before we draw conclusions from these criteria it is important to note that this single course has been used as an example in developing strategy for continuous improvement of the design curriculum. The study draws conclusion on the effectiveness of a single course that has been stringently evaluated with such outcomes based quality criteria.

\section{Conclusions}

The data above shows the qualitative success of the course. If all the goals and objective of the course were accomplished for this course, the majority (almost 75\%) of the students' ability demonstrates higher-level confidence - "Psychomotor skill quality." At this skill level students can synthesize the concept and apply the theory to practice. The behavior items are question items $3,6,9,12,15,18$ and 21 . They project selfassessment of the students' competence to solve rotation problems (mean score $=4$ ), fabricate (mean score $=4)$, evaluate (mean score $=4$ ), demonstrate (mean score $=4)$, apply (mean score $=4$ ), exhibit pride (mean score $=4)$, of applied engineers, (mean score $=4)$. Similarly the result can be interpreted in terms of Cognition and Affective Skill, which when computed are in the range of 4 to 5 . This explains the fact that the students have demonstrated a definite progress toward success.

The above summary is a qualitative evaluation of a single course depicting the efforts to integrate the design curriculum with a comprehensive and unifying design software. Twenty final year students in a capstone "Machine and Tool Design" course used the robust design software. At he culmination of the course they were asked about their design skill experience and the effectiveness of the course. The survey revealed "Student learning and professional design development was enhanced with the use of an effective $\mathrm{cad} / \mathrm{cam}$ integration tool that enabled students to synthesize design problems, which were challenging and practical." The result of this research is crucial to the Accreditation Board for Engineering and Technology's (ABET-2000) outcome based evaluation criteria and its implementation.

\section{References}

[1] The learning Curve, Solidworks Newsletter, Winter/Spring 1999

[2] Cronbach, L.J., Evaluation of Educational and Social Programs, Jossey-Bass Publications, Los Angeles, CA 1983

[3] Newcomer, K. E., Asking Appropriate Questions Appropriately," Evaluation News, November 85

[4] Schon, D.A. The reflective practitioner. Basic Books, New York. 1983

[5] Ross, D. D. \& Kyle, D. W. (1987) Helping pre-service teachers to use teacher effectiveness research appropriately. Journal of teacher education. 38 (2), 40-45.

\section{Hamid Khan}

Hamid Khan is an Assistant Professor in the School of Industry and Technology of East Carolina University. His teaching interest is focused on Computer Aided Machine and Tool Design, Computer Graphics, Concurrent Engineering in Mechanical Design, and CAD/CAM/CAE/and RP. His research interest is focused on the above as well professional development of Professional Engineering and Technology Managers to integrate teaching for practice. Dr. Khan has a BS in Mechanical Engineering, an MS in Industrial and Management Systems Engineering, an MBA in Production Strategy and a Doctorate in Management Education. Hamid is a Registered Professional Engineer. He is active in the ASEE's Engineering Technology Division, Educational Research and Methods Division, and Computers in Education Division. He is also active in IEEE/Frontiers in Education conferences. He has published and presented about twenty-five papers in their annual proceedings and conferences. Hamid has served as a reviewer for the ASEE's ERM, International, manufacturing Divisions for the Frontiers in Education proceeding papers. He has served as a judge for International Design competitions conducted annually by the auspices of Addison Wesley/Engineering Design Graphics Division of ASEE and as a reviewer for Ben Dasher best paper award nominations for the Frontiers in Education. 